\section{MODERNIDADE, TERROR E POLÍTICA DA MORTE}

\section{Ricardo Pagliuso Regatieri *}

MBEMBE, Achille. Necropolítica. São Paulo: n-1 edições, 2018.
O ensaio Necropolítica, de Achille Mbembe (2018 a), foi originalmente publicado em inglês (em tradução do lamba, língua bantu falada na fronteira da Zâmbia com o Congo, por Libby Meintjes) na revista norte-americana Public Culture em 2003. Em português, apareceu na revista brasileira Arte $\mathcal{F}$ Ensaios em 2016, com tradução de Renata Santini. É a tradução de Santini, com algumas readequações em relação à versão de 2016, que a n-1 edições publicou como um pequeno livro em 2018. No mesmo ano, a editora também lançou no Brasil Crítica da razão negra, livro de Mbembe (2018 b) cujo original saiu em francês em 2013. Nessa obra, o autor investiga a gênese e as transformações da categoria negro no período que vai desde o tráfico atlântico de escravos até o neoliberalismo e a globalização do início do século 21. Nascido nos Camarões em 1957, Achille Mbembe fez seu mestrado e doutorado na França nas áreas de História e Ciência Política. Atualmente, é professor no Instituto de Pesquisa Social e Econômica da University of the Witwatersrand na África do Sul e professor visitante na Duke University nos Estados Uni-

* Universidade Federal da Bahia (UFBA)

Rua Professor Aristides Novis, 197, Federação. Cep: 40210630. Salvador - Bahia - Brasil. ricardo.pagliuso@ufba.br https://orcid.org/0000-0003-0625-8275 dos. Desde pelo menos a publicação da coletânea de ensaios Sobre a pós-colônia em francês em 2000 e em inglês no ano seguinte (o livro ainda não existe em português), as ideias de Mbembe têm despertado crescente interesse e debate no mundo acadêmico francófono e anglófono. Essa coletânea, cujos textos se interligam pela ideia da "banalidade do poder" na África contemporânea, inicia um ciclo de reflexão que Mbembe completa com Crítica da razão negra e ao qual pertence Necropolítica. Com as traduções da editora paulista, Mbembe entra de vez no debate brasileiro.

Logo no início de Necropolítica, Mbembe enuncia a tese que irá explorar ao longo do ensaio:

Este ensaio pressupõe que a expressão máxima da soberania reside, em grande medida, no poder e na capacidade de ditar quem pode viver e quem deve morrer. Por isso, matar ou deixar viver constituem os limites da soberania, seus atributos fundamentais. Ser soberano é exercer controle sobre a mortalidade e definir a vida como a implantação e manifestação de poder (Mbembe, 2018a, p. 5).

Mbembe constrói sua noção de necropolítica ou política da morte a partir de uma articulação da problematização da biopolítica com discussões sobre soberania e estado de exceção, lançando mão, para isso, entre outros, de autores como Michel Foucault (1999; 2005), Carl Schmitt (2013) e Hannah Arendt (2012). Na primeira parte de seu ensaio, Mbembe propõe a ideia que será, por assim dizer, sua espinha dorsal, qual seja, a de que "experiências contemporâneas de destruição humana sugerem que é possível desenvolver uma leitura da política, da soberania e do sujeito, diferente daquela que herdamos do discurso filosófico da modernidade" (Mbembe, 2018a, p. 11). Em vez de "considerar a razão a verdade do sujeito, podemos olhar para outras categorias fundadoras menos abstratas e mais palpáveis, tais como a vida e a morte" (Mbembe, 2018a, p. 11). É nessa proposição de Mbembe, a de decifrar a modernidade antes como ligada à gestão da morte e da vida do que como um projeto 
de autonomia, reconhecimento intersubjetivo e liberdade, que reside a força de seu ensaio.

Na segunda parte, Mbembe começa a propriamente relacionar biopoder, soberania e estado de exceção, sendo justamente essa combinação que compõe seu conceito de necropolítica. É nessa parte de sua exposição que fica clara a ligação entre a modernidade e o terror. Para tratar do entrelaçamento de modernidade e terror, Mbembe discute a experiência colonial. Na colônia, concatenam-se o biopoder que separa e classifica as raças, o direito soberano de matar e o estado de exceção normalizado como regra. Apoiando-se em Foucault, Mbembe escreve que a biopolítica da raça "pressupõe a distribuição da espécie humana em grupos, a subdivisão da população em subgrupos e o estabelecimento de uma cesura biológica entre uns e outros" (Mbembe, 2018a, p. 17). Segundo Mbembe, “a raça foi a sombra sempre presente sobre o pensamento e na prática das políticas do Ocidente, especialmente quando se trata de imaginar a desumanidade de povos estrangeiros - ou a dominação a ser exercida sobre eles" (Mbembe, 2018a, p. 18). Nesse ponto, ainda que trilhando outros caminhos teórico-metodológicos, a argumentação de Mbembe se aproxima da ideia de Aníbal Quijano (2005) de que a aurora da modernidade implicou a hierarquização racial levada a cabo pelo colonialismo europeu em expansão.

As raízes de regimes de segregação e terror que tiveram lugar no século $\mathrm{XX}$, como o ลิ nazismo e o apartheid, podem ser encontradas não estivesse sujeito a qualquer regra. A ideia de que "a colônia representa o lugar em que a soberania consiste fundamentalmente no exercício de um poder à margem da lei (ab legibus solutus)" perpassa, segundo Mbembe, o pensamento filosófico moderno assim como a prática e o imaginário político europeus" (Mbembe, 2018a, p. 32-33). Para ele, tal visão "corresponde à definição de soberania proposta por Carl Schmitt no início do século XX, nomeadamente, o poder de decidir sobre o estado de exceção" (Mbembe, 2018a, p. 33). Funcionando em conjunto, os dispositivos da raça, da soberania e do estado de exceção produzem aquilo que Mbembe chama de política da morte.

$\mathrm{Na}$ terceira, quarta e quinta partes do livro, Mbembe se ocupa de dois casos de exercício do necropoder na fase mais recente da modernidade: a ocupação colonial tardia de Gaza e da Cisjordânia por Israel, que gera duas lógicas que se confrontam - a lógica do martírio e a lógica da sobrevivência -, e as máquinas de guerra nos países africanos contemporâneos. No primeiro caso, tem lugar uma ocupação que fragmenta o território, isolando pessoas e sitiando vilas e cidades, bem como instituindo a obrigatoriedade de autorizações formais para o deslocamento entre os espaços fragmentados. Isso visa "impossibilitar qualquer movimento e implementar a segregação à moda do Estado do apartheid" (Mbembe, 2018a, p. 43). A infraestrutura de estradas, pontes e túneis é construída de maneira a separar os fluxos de palestinos e israelenses, evitando que uns e outros se cruzem. No ar, helicópteros fazem patrulha permanente e estão sempre prontos a matar. Em terra, tratores blindados são usados para intimidação e para levar a cabo uma política de terra arrasada. No cotidiano militarizado que se estabelece, outorga-se "liberdade aos comandantes militares locais para usar seus próprios critérios sobre quando e em quem atirar" (Mbembe, 2018a, p. 48).

A narrativa israelense é a de que seu "Estado tem o direito divino de existir", e ela "entra em competição com outra narrativa 
pelo mesmo espaço sagrado" (Mbembe, 2018a, p. 42). Em virtude da posição desigual em que se encontram palestinos e israelenses nessa disputa, a narrativa de cada uma das partes produz um tipo distinto de lógica: do lado palestino, a lógica do martírio e, do lado israelense, a lógica da sobrevivência. Enquanto na lógica do martírio, cuja figura prototípica é o homem-bomba, a "vontade de morrer se funde com a vontade de levar o inimigo consigo, ou seja, eliminar a possibilidade de vida para todos", na lógica da sobrevivência, cuja base é o argumento do Estado de Israel de que vive sob ameaça constante de destruição, trata-se de "querer impor a morte aos demais, preservando a própria vida” (Mbembe, 2018a, p. 64). Em comum entre elas, está o fato de ambas operarem com base no terror e na morte. Pela destruição, cada uma das lógicas busca afirmar sua divindade e sua identidade nacional.

Na África, durante o último quartel do século XX e "em relação direta com a erosão da capacidade do Estado pós-colonial de construir os fundamentos econômicos da ordem e autoridade políticas" (Mbembe, 2018a, p. 55), Mbembe vê surgir aquilo que, seguindo Deleuze e Guattari (1997), ele chama de máquinas de guerras. No contexto da incapacidade de muitos desses Estados de fazer valer o monopólio sobre a violência, a coerção e a gestão de seus territórios, emerge, em seu lugar, [eliminar espaçamento] um mosaico de direitos de governar incompletos e sobrepostos, disfarçados e emaranhados, nos quais sobejam diferentes instâncias jurídicas de facto geograficamente entrelaçadas, e nas quais abundam fidelidades plurais, suseranias assimétricas e enclaves (Mbembe, 2018a, p. 52).

As máquinas de guerra são organizações móveis, difusas e polimorfas, constituídas por "segmentos de homens armados que se dividem ou se mesclam, dependendo da tarefa e das circunstâncias" (Mbembe, 2018a, p. 54). Elas reúnem características, ao mesmo tempo, de uma organização política e de uma empresa mercantil, operando "mediante capturas e de- predações" (Mbembe, 2018a, p. 54-55) e mantendo relações complexas com as formações estatais, que vão da autonomia à incorporação. A formação das máquinas de guerra está associada a uma "nova geografia de extração de recursos", particularmente à exploração predatória de minerais, que dá origem a enclaves e à formação de milícias. Esses enclaves se convertem, segundo Mbembe, em "espaços privilegiados de guerra e morte" (Mbembe, 2018a, p. 57). Nessas áreas, a lógica da extração e do saque dos recursos naturais pelas máquinas de guerra engendra "tentativas brutais para imobilizar e fixar espacialmente categorias inteiras de pessoas ou, paradoxalmente, para soltá-las, forçando-as a se disseminar por grandes áreas que excedem as fronteiras de um Estado territorial” (Mbembe, 2018a, p. 58).

Ao relacionar modernidade, terror e política da morte, a discussão de Mbembe em $\mathrm{Ne}$ cropolítica sintoniza-se com projetos críticos que foram desenvolvidos ao longo do século XX, como os da primeira geração da Escola de Frankfurt ${ }_{1}$ (que ele não mobiliza ) e o de Foucault, e a orientações mais recentes, como as críticas decolonial e pós-colonial (Mbembe afirma não se encaixar nesse último rótulo), fornecendo sem sombra de dúvida elementos instigantes para uma teoria social crítica do presente. Sua ênfase no lado eclipsado do moderno, desde a aurora do mundo colonial até a ocupação de Gaza e da Cisjordânia e a guerra permanente em África, coloca-o como antípoda do otimismo liberal-iluminista de teóricos como Jürgen Habermas (2000). No entanto, os limites de seu texto provêm justamente de onde procede boa parte de sua força, nomeadamente de sua herança pós-estruturalista francesa. Isso o impede de, por exemplo, se apropriar do que há de melhor no marxismo crítico do século passado, produzido sobretudo em língua alemã, e o leva a considerar Marx (2011), Bukharin (1979), Lênin (1977) e Trotsky (1969) a mesma coisa, quando por exemplo afirma ${ }^{1}$ Penso aqui sobretudo nos trabalhos de Walter Benjamin (1985) e Max Horkheimer e Theodor Adorno (1997). 
que o marxismo clássico buscava "erradicar a pluralidade da condição humana”, na medida em que o "sujeito da modernidade marxista é, fundamentalmente, aquele que tenta provar sua soberania pela encenação de uma luta até a morte" (Mbembe, 2018a, p. 26), citando, para confirmar seu argumento, Bukharin, Lênin e Trotsky. Tal procedimento é típico do pós-estruturalismo francês, que nunca conseguiu separar Marx e o marxismo crítico das vulgatas do Partido Comunista Francês. Afora isso, deve-se reconhecer que Mbembe é uma das mais importantes vozes críticas de um pensamento que tem buscado superar o eurocentrismo na teoria social.

Recebido para publicação em 21 de outubro de 2020 Aceito em 14 de novembro de 2020

\section{REFERÊNCIAS}

ARENDT, Hannah. Origens do totalitarismo. São Paulo: Companhia das Letras, 2012.

BENJAMIN, Walter. Sobre o conceito da História. In: BENJAMIN, Walter. Magia e técnica, arte e política: ensaios sobre literatura e história da cultura. Obras Escolhidas, volume 1. São Paulo: Brasiliense, 1985.

BUKHARIN, Nikolai. The Politics and Economics of the Transition Period. London: Routledge \& Kegan Paul, 1979.
DELEUZE, Gilles; GUATTARI, Felix. Mil platôs. Capitalismo e esquizofrenia. São Paulo: Editora 34, 1997.

FOUCAULT, Michel. Vigiar e punir. Petrópolis: Vozes, 1999. Fontes, 2005.

Em defesa da sociedade. São Paulo: Martins HABERMAS, Jürgen. O discurso filosófico da modernidade. São Paulo: Martins Fontes, 2000.

HORKHEIMER, Max; ADORNO, Theodor W. Dialética do esclarecimento. Rio de Janeiro: Jorge Zahar, 1997.

LENIN, Vladimir Ilitch. Selected Works, volume 2. Moscow: Progress Publishers, 1977.

MARX, Karl. A guerra civil na França. São Paulo: Boitempo, 2011.

MBEMBE, Achille. De la postcolonie. Essai sur l'imagination politique dans l'Afrique contemporaine. Paris: Éditions Karthala, 2000.

Necropolítica. São Paulo: n-1 edições, 2018a. $2018 \mathrm{~b}$. Crítica da razão negra. São Paulo: n-1 edições,

QUIJANO, Aníbal. "Colonialidade do poder, eurocentrismo e América Latina”. In: LANDER, Edgardo (Org.). A colonialidade do saber: eurocentrismo e ciências sociais. Perspectivas latino-americanas. Buenos Aires: CLACSO, 2005.

SCHMITT, Carl. La dictadura. Madrid: Alianza Editorial, 2013.

TROTSKY, Leon. Terrorismo e comunismo. Rio de Janeiro: Saga, 1969. doutorado sanduíche na Goethe-Universität Frankfurt. Professor do Departamento de Sociologia e do Programa de Pós-Graduação em Ciências Sociais da Universidade Federal da Bahia. Líder do PERIFÉRICAS - Núcleo de Estudos em Teorias Sociais, Modernidades e Colonialidades, vinculado à Faculdade de Filosofia e Ciências Humanas da UFBA e inscrito no CNPq. Desenvolve pesquisas nas áreas de teoria sociológica, teorias críticas, colonialidade e modernidade. É autor dos livros Negatividade e ruptura (Annablume, 2012) e Capitalismo sem peias (Humanitas, 2019), bem como de artigos publicados em revistas do Brasil e do exterior. 